www.periodicos.unimontes.br/index.php/caminhosdahistoria

\title{
TERRITÓRIOS, REVISÕES DE PROPRIEDADE E PLEITOS PUEBLERINOS: A PRÁXIS DE COLONIZAÇÃO DA COMPANHIA DE JESUS NA PROVÍNCIA DO PARAGUAI (SÉC. XVII-XVIII)
}

\author{
Rodrigo Maurer ${ }^{1}$
}

\begin{abstract}
Resumo: Este ensaio perfaz uma análise dos procedimentos adotados pela Companhia de Jesus no que tange a elaboração da Província do Paraguai; voltando-se especialmente para as situações dos pleitos pueblerinos, em regra, indisposições formais por territórios mal definidos ou sobre produtos de subsistência principal da época: o gado. Indica ainda, os procedimentos e as táticas utilizadas pelos religiosos naquilo que se entende como divergências de ordem jurídico-convencional e que tiveram de ser contornadas, para que não comprometessem o desenvolvimento reducional. Logo, a definição do contexto histórico repousa numa estratégia colonial: confundir os laços de pertencimento daquelas comunidades. Até o momento, os estudos sobre as reduções índio-jesuíticas do Paraguai não formularam uma hipótese mais sistemática sobre tais episódios. Diante da necessária abordagem, eis que esboçamos um panorama dos principais instrumentos ou das estratégias mantidas naquelas circunstâncias e seus efeitos quando dos territórios em disputa (leia-se) "territórios de memória", que o projeto católico modificou intensamente com vistas a consagrar o propósito de conquista.
\end{abstract}

Palavras-chave: Práticas de Antigo Regime; História colonial; experiências de longa duração; marcadores territoriais; narrativa jesuítica.

Abstract: This essay makes an analysis of the procedures adopted by the Companhia de Jesus regarding the elaboration of the Province of Paraguay; turning especially to the situations of pueblerino claims. As a rule, formal indispositions over illdefined territories or over main subsistence products of the time: cattle. It also indicates the procedures and tactics used by the religious in what is understood as divergences of a legal-conventional order and that had to be circumvented to customs that did not compromise the reductive development. Therefore, the definition of the historical context rests on a colonial strategy: to confuse the ties of belonging of those communities. So far studies on Paraguay's Indian-Jesuit reductions have not formulated a more systematic hypothesis about such episodes. In view of the necessary approach, behold, we have outlined an overview of the main instruments or strategies maintained in those circumstances and their effects in the disputed territories (read) "territories of memory" that the Catholic project has intensively modified in order to enshrine the purpose of conquest.

Keywords: Practices of Old Regime; Colonial History; long-term experiences; territorial markers; Jesuit narrative.

1 Doutorando do PPG em História da UFSM, Santa Maria, RS. Bolsista Capes Brasil. Email: ferreiramaurer@bol.com.br. ORCID: https://orcid.org/0000-0002-5778-303X. 


\title{
Das terras a perder de vista aos territórios de memória: A narrativa do conflito como parte do todo ${ }^{2}$
}

\begin{abstract}
Ocurren algunas diferencias y pleitos. Los más ordinarios son sobre límites de tierras, porque aunque hay títulos de ellas, dados y firmados de los Gobernadores en nombre del Rey, suelen con el tiempo mudarse los nombres de ríos o cerros, etc., linderos de las tierras, de que se siguen dudas y diferencias. [...] Hacen su papel los indios: hace el Cura el suyo: preséntanlo a los jueces: cotejan las dos partes, y deciden a pluralidad de votos: y con eso, sin más gastos, se acaba todo.
\end{abstract}

Joseph Cardiel

Nas "últimas nações da América" (JARQUE, [1687] 2008, p. 43), foi comum os jesuítas fazerem uso da expressão pleito pueblerino para retratar situações de desconforto entre duas ou mais reduções. No tocante da questão histórica, que não é meramente convencional, o que vamos expor na sequência condiz em primazia de povos com fisionomias próprias que tiveram seu curso histórico interrompido.

Obstante, de longe podem representar meras exceções, todavia, ilustram uma práxis de poder interno que parece corroborar a uma autonomia equivalente, talvez mantido a um conjunto de improvisações que tiveram de ser repetidamente reajustadas quando ainda condicionadas a preencher as individualidades que compunham cada localidade. Na esteira disso, contudo, diminuindo a importância dos casos, Alberto Armani concluiu certa feita que:

A veces surgían conflictos entre una misión y otra, pese a los vínculos de solidaridad que lentamente habían ido ligando a las treinta Reducciones. En general se trataba de disputas concernientes al derecho de disponer de pasturas, o bien, de controversias comerciales. Para resolver estos problemas no era suficiente el juicio de un solo sacerdote, de modo que se recurría a una comisión de misioneros preferiblemente residentes em poblados muy distantes de los que estaban involucrados en el pleito. En los casos más importantes - por ejemplo cuando se trataba de discusiones de límites - la comisión estaba presidida por el superior de las Reducciones. Al igual que en el campo administrativo, en el judicial los misioneros actuaban dentro del marco de las leyes españolas (ARMANI, 1996, pp. 109-110).

Em regra e ao contrário do que ficou sintetizado, a Companhia de Jesus que se apresenta por intermédio dos pleitos deixa entender que os seus representantes trataram de resolver os conflitos de modo reservado, sem fazer uso de instrumentos que pudessem lhes expor diante da corte espanhola ou de outras instâncias jurídicas européias. Longe de uma orientação casuística, aquelas situações sequer tiveram uma legislação específica de modelo

\footnotetext{
${ }^{2}$ As avaliações conferidas nesse artigo tratar-se-iam de extratos de uma investigação de maior fôlego, no caso, a tese de doutoramento que tem por tema de pesquisa "os pleitos pueblerinos, o estado jesuítico e a utopia desperta ao feito da transformação", sob orientação do Prof. Dr. Júlio Ricardo Quevedo dos Santos. A contar daí, o conteúdo não foge muito do que estamos a avaliar a médio prazo de maneira mais detida.
} 
para cumprir. No máximo, o que tais decisões acompanhavam eram as determinações que partiam do Colégio de Córdoba. E numa rara demonstração, ao que parece de exceção, teve de ser solicitado auxílio a Roma - haja vista que o próprio colegiado de juízes apresentou-se incapaz de alcançar uma solução definitiva para o impasse. E o motivo alegado, na época, alinhou-se ao fato de que faltariam "doutores em direito" na Província do Paraguai.

É neste sentido que procuramos demonstrar de que não há como, genericamente, estipular uma racionalidade padronizada ou ainda uniforme para circunstâncias que mais parecem indicar um aproveitamento consentido e voluntário, por grande parte dos religiosos, no sentido de modificar não só os territórios como também as minorias étnicas que por entre aqueles "territorializavam-se" e eram, por consequência, "territorializadas"3.

Naquele que é um dos raros rabiscos que ilustram o horizonte colonial projetado para aquelas comunidades, é possível se ter uma idéia inicial do contexto que chamamos atenção ${ }^{4}$ :

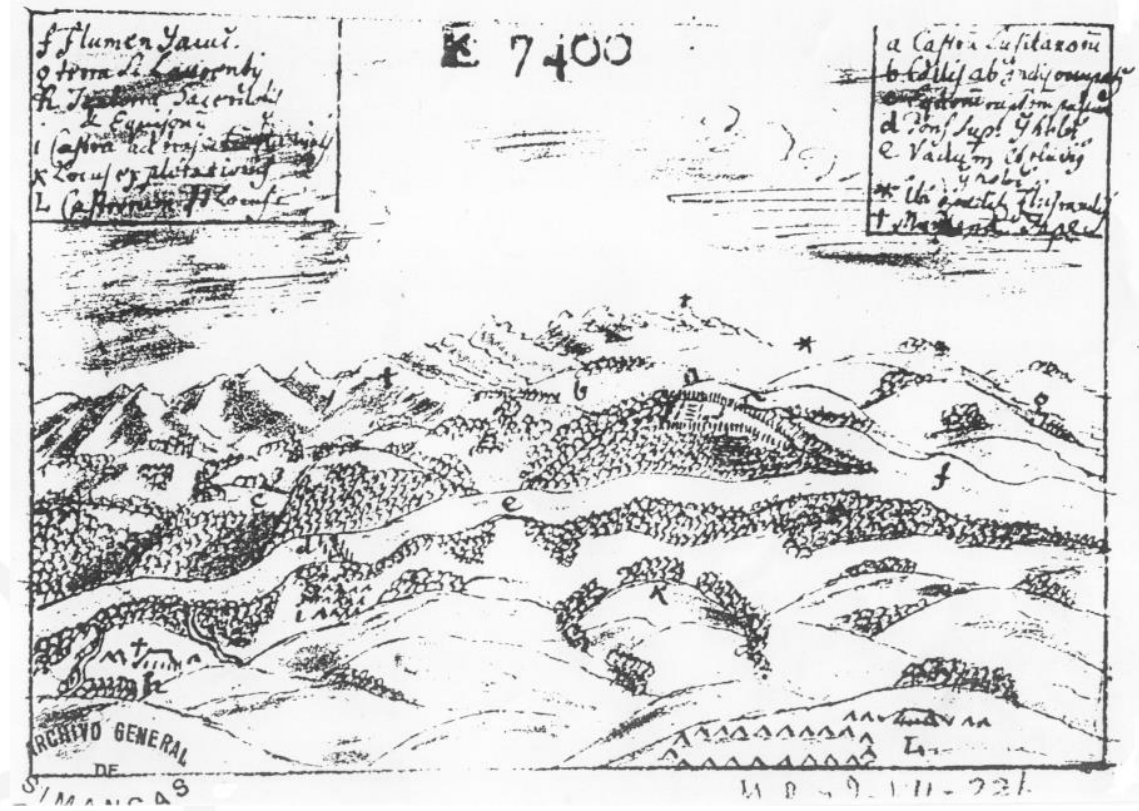

Pelo esboço fica fácil entender que os limites entre reduções pautavam-se em acidentes geográficos, como rios, açudes, morros, capões de mato e outros componentes que o meio apresentava como barreiras a serem superadas ou quando ainda reconhecidas. Aliás, se tirarmos por proveito a reação do bávaro Anton Sepp, aquelas situações de indiferença mostravam-se expressamente normais, uma vez que, "a razão e as causas principais eram a

\footnotetext{
${ }^{3}$ Grosso modo, a territorialização seria o ato de o índio manter a autenticidade mesmo num cenário modificado. Em todo caso para saber mais, consultar: PACHECO DE OLIVEIRA, 1997.

${ }^{4}$ Imagem retirada de BARCELOS, 2006, p.141. Mapa que se halló incluso en este Diario, el que se conoce por la letra estar delineado p.r el P. Thadeo Xavier Enis de la Compañía de Jesús. Prancha VII 221.
} 
demasiada vizinhança de ambos os povos e, por conseguinte, fáceis demais para furtos de ambos os lados" (SEPP, [1697] 1972, p. 155).

Sucede que, proporcionalmente, a "realidade em transformação" mantida ao labore jesuítico formulou nos povos originários a "consciência" de distribuirem-se aleatoriamente em meio ao horizonte que dispunham. Por tais circunstâncias, não é possível precisar um ponto característico desse entendimento, uma vez que muito raramente reportam ao sentido original daquelas sentenças.

A situação que tem se mostrado mais recorrente nos documentos trabalhados, a rigor simplifica que as disputas entre povos davam-se de modo oficial perante um Colegiado ${ }^{5}$. E a este colegiado competia pela responsabilidade de reconhecer e oficializar as decisões. O historiador Artur Barcelos, traduziu em poucas palavras os procedimentos adotados nos episódios em questão:

Inicialmente, cabia aos Provinciais a nomeação de três padres das reduções do Rio Paraná e três padres das reduções do Rio Uruguai para atuarem como juízes. Como forma de garantir a não interferência de interesses pessoais, os juízes nomeados para o Rio Paraná atuariam nos pleitos do Rio Uruguai, e aqueles do Uruguai atuariam nos pleitos do Paraná. No caso de haver um pleito entre reduções dos dois rios, o trio de juízes seria formado por um representante do Uruguai e outro do Paraná, sendo o terceiro o Padre Superior. Se este, por alguma razão, se considerasse impedido, realizar-se-ia uma eleição junto aos seus consultores para a nomeação de um terceiro juiz. Após serem realizadas as diligências necessárias, com a análise dos documentos apresentados pelas partes envolvidas e a visita aos locais em disputa, caberia aos juízes proferir uma sentença. Concedia-se dois meses de prazo para que, em caso de apelação, as partes se pronunciassem. Todos os documentos gerados pelo processo deveriam então ser entregues ao Superior, que os presidiria uma reunião que, após o exame de toda a documentação, realizaria uma votação, cujo resultado deveria ser a sentença definitiva e irrevogável (BARCELOS, 2006, p. 450).

Isso equivale dizer que o contexto, em termos mais precisos, alinha-se a curiosos inconformismos que tiveram de ser exteriorizados em formato de defesa. Conquanto, a variedade de episódios que por ora investigamos $(10 \text { ao total })^{6}$ e por conseguinte as diferenças contidas ao conteúdo, não significam propriamente, que toda a contrariedade revertesse numa

\footnotetext{
${ }^{5} \mathrm{O}$ colegiado conforme observações aferidas pelo Padre Provincial Thomas de Baeza, foi condicionado à prática em 1721. A sua aplicabilidade, quando acionado, era conduzido pelo Padre Superior (maior representação e também o voto de minerva em muitas ocasiões), pelo padre provincial e um padre corregedor. As discussões eram acompanhadas pelos padres responsáveis das reduções (curas) e por dois representantes dos cacicados envolvidos.

${ }^{6}$ Para fins de registro tem-se os seguintes pleitos mapeados: (S. Xavier x Concepción); (Yapeyu x La Cruz); (Santo Thome x S. Miguel); (San Miguel x Nra. Señora de Loreto); (San Miguel x S. Juan Bauptista); (Jesus Maria dos Guenoas x S. Nicolás); (Santa Ana x San Nicolás); (S. Miguel x S. Luís); (San Miguel x Concepción). Sabemos da existência de um $10^{\circ}$ caso que acabou envolvendo quatro pueblos (Santa Ana, S. Cosme, Candelaria e S. Joseph).
} 
sentença definitiva e irrevogável como chegou a a advertir Artur Barcellos. Ao contrário disso, diríamos que com raras exceções não foi solicitada a revisão daquelas sentenças. $\mathrm{O}$ contexto, no que pese o aproveitamento a ser acompanhado, remete a uma junção complicada de manifestações. Ao passo que, algumas atitudes permitem comparações, outras nem tanto.

E os desconfortos que potencialmente configuram parte dos casos, se assim forem compreendidos, corroboram a uma lista de desordens advindas de uma resistência que parece ter sido compreendida na sua plenitude desde as primeiras iniciativas de conquista.

É evidente, por conseguinte, que a ilustração reducional definiu uma nova orientação, ou melhor, fez desaparecer o envolvimento de outrora dos quais os indígenas dominavam com maestria de modo a substituí-lo por ambições coniventes aos interesses dos seus instrutores. E o lugar onde essa manifestação se revela mais flagrante é justamente nas situações de desconforto. Tidas como esforços indiscutíveis de causas supostas, talvez seja útil buscar compreendê-las como motivações que tiveram de ser contornadas, ou como bem resumiu o padre superior Bernardo Nusdorfer, tratar-se-iam de "uma conquista continuada" (NUSDORFFER, Bernardo [1737] editado por FURLONG, Guillermo 1962, p. 631).

\section{Pleito entre Yapeyu e La Cruz ${ }^{7}$}

As descrições sugeridas a este litígio demonstram que o ponto de partida levou em conta uma doação de um potreiro, feita pelo povo de Yapeyu à Assuncion del Bororé (reconhecimento primevo do povo de La Cruz, mantido até os ataques bandeirantes da quarta década do século XVII) ${ }^{8}$.

\footnotetext{
${ }^{7} \mathrm{O}$ conteúdo a seguir faz parte de uma documentação específica que trata tão só do pleito em destaque. Por isso, toda vez que a nossa escrita intercalar uma citação em espanhol com a língua portuguesa é de modo a consagrar um extrato daquela, o que pode ser conferido em A.G.N.A. Sala IX: 6.9.4. Compañía de Jesús. A redução de Yapeyu também referida como S.S. Reyes del Yapeyu, foi fundada em 1626. A edificação de La Cruz se atesta como 1629. As informações no que tange as fundações daqueles povoados podem ser conferidos na documentação que segue: A.G.N.A. Sala IX: 17.3.6. División colônia-sección gobierno misiones. Padrones 1735-1802.

${ }^{8}$ Para este caso, acompanhar: KERN, 1984; MAEDER, 1989.
} 


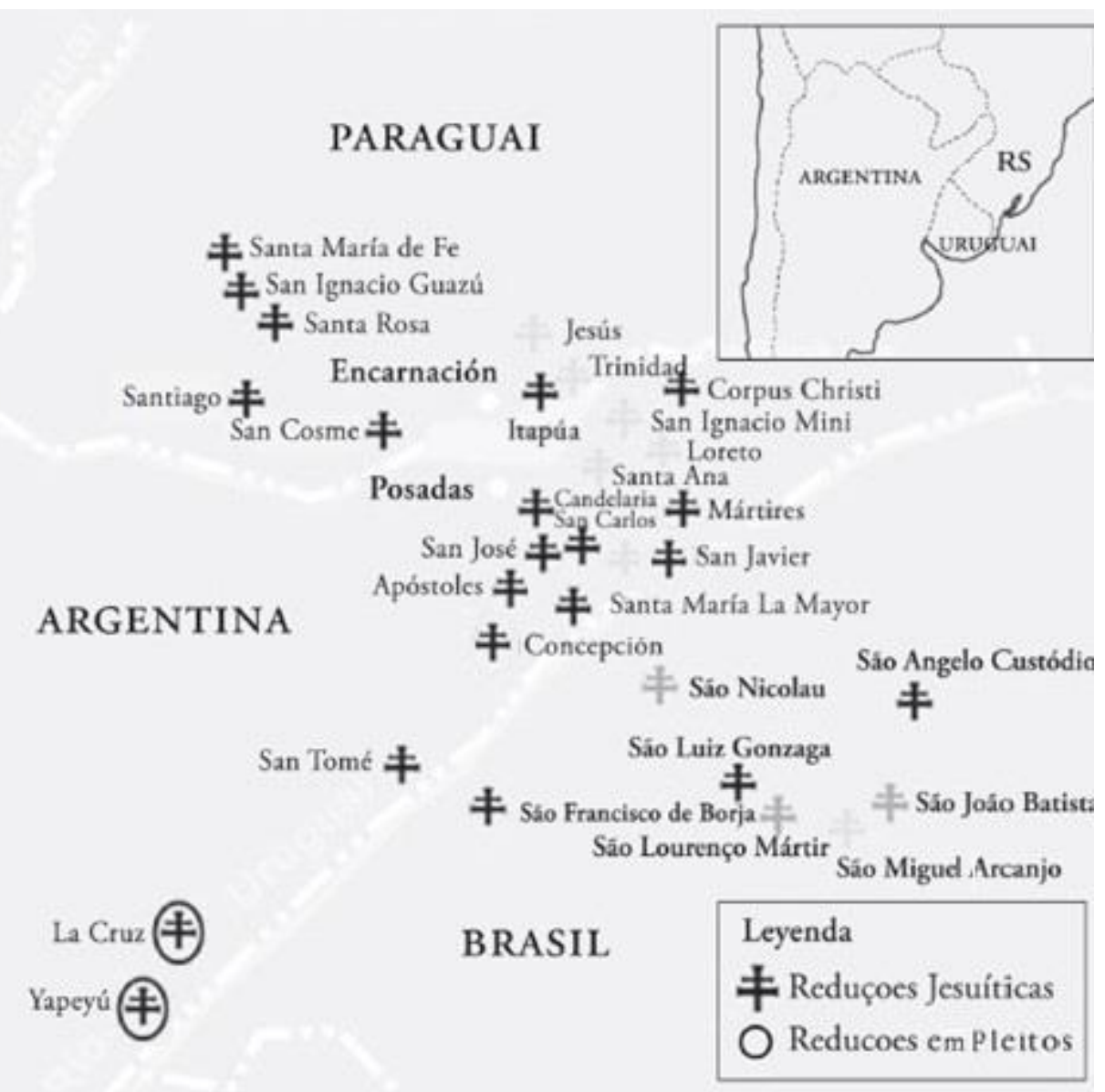

Fonte: Projetos Culturais do Mercosul. Apud PINTO; Muriel; MAURER, Rodrigo. Quando a geo-história avança sobre os significados de um espaço urbano: as paisagens culturais e as transformações identitárias da fronteira Brasil - Argentina. In: Eure, vol. 40, n 120, Mayo 2014: 135-158. Aqui adaptado de modo a situar a localização dos povos em pleito.

O caso, ao que consta, foi solicitado inicialmente pelo padre General Thyrso Gonzales em 17 de janeiro e teve seu despacho no dia 31 de janeiro de 1696, já contendo ajustes de outro padre, o Provincial Lauro Nuñez. A este último, coube a tarefa de deixar as partes acordadas conforme o seu entendimento do caso. E para isso foi necessário revisar as doações consentidas pelo seu antecessor [sic].

As informações, nesse caso, retiradas ao dia que seguem as suas descrições, (28.11.1699) indicam que a situação partiu de uma solicitação feita por esse mesmo personagem ao povo de Yapeyu, do qual solicitava que a redução restituísse ao povo de Assumpcion del Borore a sua posse. Entretanto, ao decorrer do episódio, chega-se ao conhecimento de que a população de La Cruz, teria sido despojada "violentamente" de algumas terras das quais comportavam o suposto potreiro. Que, salvo maiores inconvenientes, tivera sido confirmado inicialmente por outro personagem, o então padre Provincial Thomas Donvidas, contudo, o território em questão teve de passar por uma reavaliação da qual levou o seu sucessor, Simon de Leon, a alterar e mudar o potreiro de lugar. 
Diante de algumas incertezas como a localização primeva do local, o caso contou com a participação de outros mediadores para chegar-se à conclusão de que as terras desde os "princípios" eram de reconhecimento a Yapeyu. Entretanto, a esses mesmos mediadores creditou-se a versão de que o território vinha sendo aproveitado pelos índios de La Cruz há vários anos e de forma pacífica? ${ }^{9}$.

O teor dos argumentos demonstram que La Cruz vinha se utilizando do território desde a sua fundação. Conforme consta, o religioso Thomas Donvidas não se preocupou em definir os povos lindeiros e isso foi decisivo para que tornasse nula a sentença do caso e como tal passou a ser reconhecido à N.S. Dela Assumpcion del Borore o direito de fazer uso de um território que compreenderia do arroio Mbacaty até o rio Uruguay, excetuando um pântano que desaguaria no mesmo local denominado à época como Pembiaba - local que não se faz reconhecer perante as cartografias contemporâneas.

Para tanto em 13 de Novembro de 1696, coube ao religioso Anselmo De La Matta, confirmar que o povo de Yapeyu teria lhe apresentado provas de direito, mediante algumas terras que estariam dentre o Ytaqui e Piratini, Uruguay e Ybicuý, que com o tempo passaram a ser tratadas como fronteiras de La Cruz, conforme colocações do mesmo. O religioso confirmou ainda que havia levado em conta um translado autêntico, assim praticado pelo então padre Superior Christoval Altamirano.

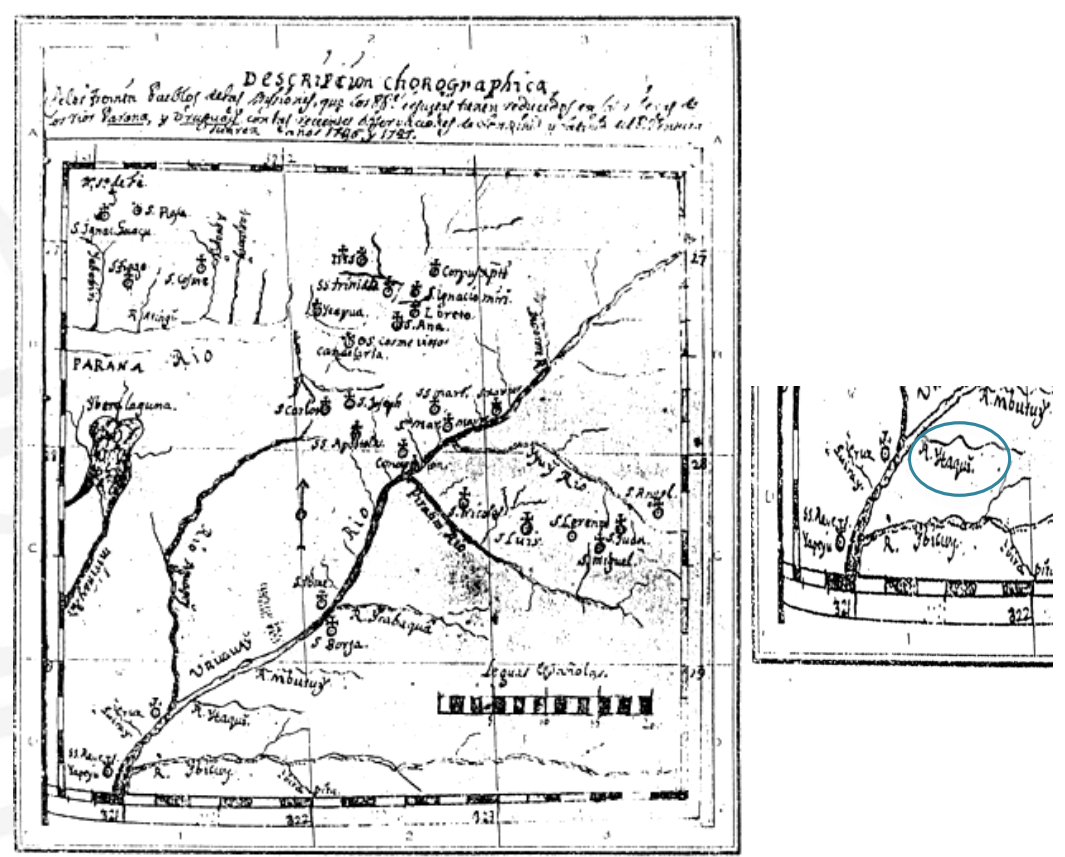

Fonte: Descripcion Chorographica de los treinta pueblos de las Misiones que los PP. ${ }^{\text {es }}$ Jesuitas tienen reducidos en las riberas de los rios Paraná y Uruguay con las recientes observaciones de Longitude y Latitud del P. Bonaventura Suarez años 1746 y 1747. FURLONG, Guillermo. 1936, Lâmina XL, n. de Catálogo 91, p. 115 do

\footnotetext{
${ }^{9}$ A esse reconhecimento foi solicitado o auxílio Joseph Serrano Francisco de Medina, Policarpo Puffo e também Pablo Caño. Todos devidamente reconhecidos pelos cabildos em questão.
} 
texto. No detalhe reduzido um dos raros registros do Rio Itaqui, rio este que acabou relegado ao esquecimento com o decorrer dos anos do projeto reducional.

O conteúdo relatado indica ainda que os cruzistas tiveram sua mobilidade controlada, haja vista que, foram orientados a impedir a passagem de gados às mediações do terreno em conflito. Determinação semelhante já havia sido empregada para impedir o cultivo de sementeiras. Motivo pelo qual acabou por se tornar no conteúdo principal firmado no povo de Santo Thomé em 23 de fevereiro de 1663. De modo a evitar maiores transtornos, o padre Andres de Rada, na condição de visitador, solicitou aos interessados no problema que não se mudasse nada. Situação que se manteve aparentemente solucionada até 23 de abril de 1696.

Em nosso entendimento o caso foi retomado transcorridas três décadas, visando indicar as doações mal sucedidas. E é nesse momento que os índios passam a tirar proveito no sentido de garantir o direito ou uso do território desejados desde os idos ancestrais.

Nestas circunstâncias, coube por exemplo ao padre provincial situar que valeria para a solução daquele caso, levar em consideração o antigo direito que cabia a cada redução, isto é, aquilo que ficou atestado e acordado entre as partes três décadas antes. Partindo desse pressuposto, deveriam os padres juízes desconsiderarem a política de doações promovida entre os índios. Daí por diante, o caso acabou ganhando outros contornos e como que indicando um novo concenso ao contexto foi admitido em 29 de Julho de 1696, na redução de San Lorenzo por Sebastian de Toledo, que os instrumentos deveriam levar em conta "o direito antigo" a Yapeyu, por se tratar de ser a redução matriz e que veio a dar origem para o surgimento de La Cruz. E, de modo a fortalecer as suas observações, acabou se utilizando das informações aprovadas inicialmente pelo padre provincial Simon de Leon, que não por menos já teriam sido confirmadas por Christoval Altamirano e também por Andres de Rada, que segundo consta, se mostrou favorável ao entendimento, porque não haveria para época "otro mejor ni mas bien fundado derecho".

Não obstante, as situações atestadas voltaram a ser reforçadas em San Nicolas no dia 8 de Novembro de 1696, por Anselmo de la Matta e conforme pareceres de Anselmo Francisco Berçorio e Henrique Masthe. Foi estabelecido um sentido de interpretação, por meio do qual é possível verificar que o único procedimento realmente apropriado para solucionar aqueles casos se dava num sentido de hierarquização - tanto no que compete à informação que deveria ser mantida por seus interlocutores - quanto ao reconhecimento da clivagem indígena concentrada à proposta de fundo.

É possível dizer que as descrições apresentadas por Anselmo de la Matta ganharam muita força entre seus pares, ao ponto de que as situações do conflito tiveram de ser 
(re)pensadas, de modo a acrescentar uma lista de povos que saberiam tirar proveito das mesmas "artimanhas", para negociar doações e lógicas de mercês. Essas características tiveram de contemplar um reconhecimento comum por parte dos povos de Concepción, San Xavier, S. Miguel, San Nicolas, Santo Thomé, Ytapua e Corpus.

Isto posto, coube ao religioso recomendar a seus colegas de batina que ignorassem qualquer iniciativa semelhante advinda das reduções, uma vez que, deveriam impedir o "incêndio de pleitos" que já se arrastava desde a decisão do caso [sic].

Quando tudo indicava que não restariam mais formas, para os índios de Yapeyu, manifestarem sua indisposição aos rumos adotados ao problema, na ausência de um padre responsável, apontaram os motivos por tamanhas intransigências. E, ao que se nota, foi um argumento muito convincente, haja vista que conseguiu demover a decisão. No entanto, não podemos assegurar quanto tempo aquele povo se manteve autonômo nas suas ações. Mas é possível situar que, com o passar do tempo, aqueles índios impuseram aos de La Cruz a condição de que poderiam fazer uso da terra desejada, desde que lhes fosse revertido o "paso delas barcas del Itaqui". Ou seja: entre o território que compreenderia um retorno ancestral, mais valia garantir uma zona de influência sobre o mesmo e também da mobilidade que o concentrava ou passaria a ser concentrado através do comércio.

A sequência de fatos referentes ao território em permuta demonstra claramente que outras razões tiveram de ser acrescidas ao episódio de fundo, contudo, foram tentativas evasivas e sem efeito. Entretanto, os pontos sugeridos no que concerne o descrédito perante o povo de Yapeyu, mantinham-se por conta da violência, das promessas, das ameaças e rusgas importunas praticadas por seus personagens. E as ações, segundo consta, ainda mantinham alguma violência mesmo decorridos dez anos das averiguações iniciais.

Ao conjunto, a última informação que nos é oferecida do caso é feita por Anselmo dela Matta, padre superior. E segundo consta, sua decisão foi aceita junto aos seus semelhantes de modo a garantir o sucesso do caso à sorte de Yapeyu, mesmo que para isso fosse necessário contrariar as provas apresentadas pelos cruzistas. Fato este, categoricamente ratificado em S. Nicolás no dia 13 de Novembro de 1696.

Desse modo temos, em todos os detalhes, a situação que acabou por levar aquelas comunidades ao conflito. De um lado, o interesse por continuar partilhando de um pântano, por outro, a necessidade de investir num discurso que contemplasse a vocação ganadera de caráter extensivo. Mas em nível proporcional, ocorre que o projeto reducional promoveu uma pluralidade de imaginários. 
Ao mesmo tempo, é bom que tenhamos bem esclarecido o fato retórico dos motivos que levaram a tal impasse, pois ao fundo da questão, o que temos é uma tomada de consciência demasidamente controvertida em fingir situações e forjar outras alternativas de entendimento por territórios já consagrados ao conhecimento majoritário. Repreia-se, contudo, mesmo terminado o exame da divergência, que as dificuldades mostravam-se recorrentes. E distingui-las nesse enlance histórico é expressamente difícil, pois ao alcance do que sabemos, "es siempre susceptible de mutaciones bruscas" (GRUZINSKI, 2007, p.358).

\section{Pleito entre La Concepción e San Xavier ${ }^{10}$}

Dentre todos os casos de lítigios que até o momento investigamos, consideravelmente este é o que melhor representa e traz detalhes das circunstâncias e dos procedimentos referentes na solução dos episódios e suas naturezas.

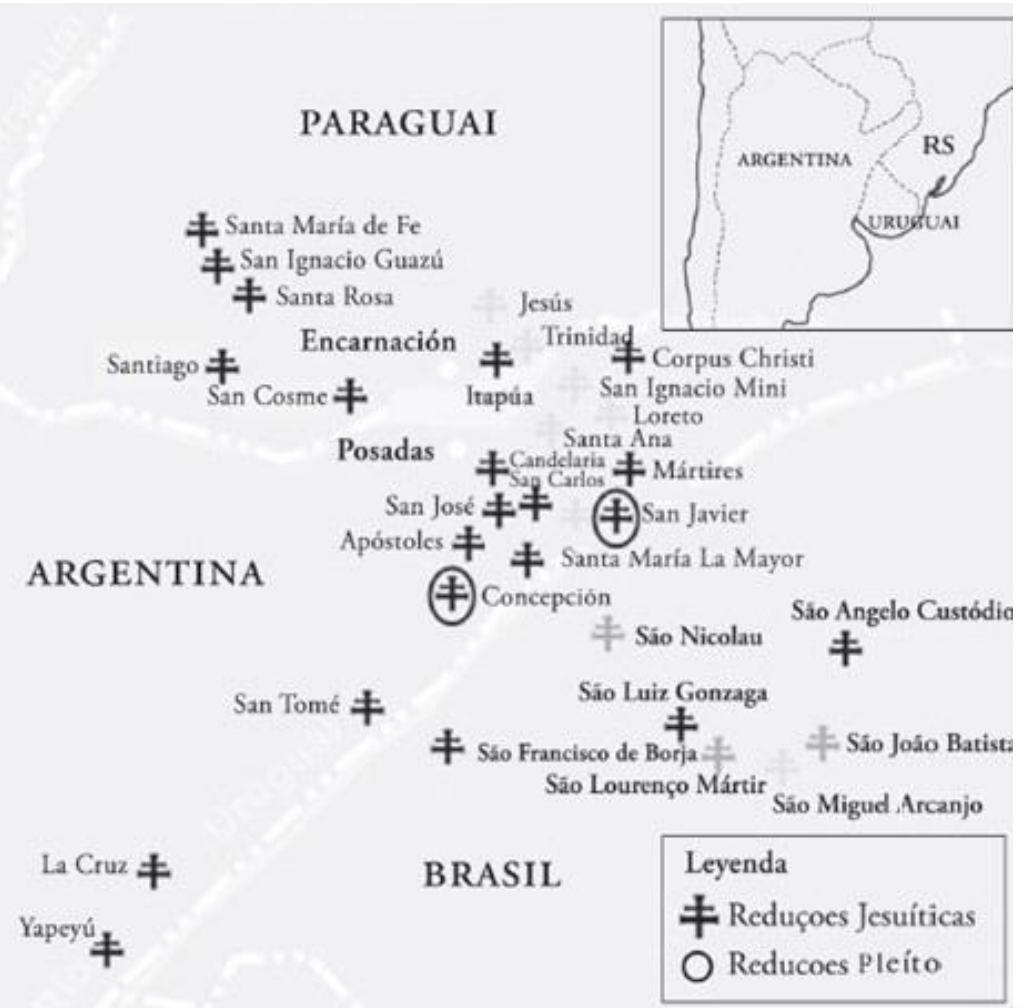

Fonte: Ib. idem.

Em 13 de março de 1697, conforme descrições de Joseph Fravia, juiz da decisão, San Xavier teria entrado com petição para rever alguns ervais que estariam de posse de Concepción e San Luis. O contexto indica que o povo de San Xavier teria feito uso constante

\footnotetext{
${ }^{10} \mathrm{O}$ teor a seguir faz parte de uma documentação específica que trata tão só do pleito em destaque. Todavia, toda vez que a nossa escrita intercalar uma citação em espanhol com a língua portuguesa é de modo a consagrar um extrato daquela. Por ordem as datas de fundações acompanham a seguinte ordem: La Concepción em 1620, San Xavier 1629. O conteúdo por sua vez pode ser conferido em: A.G.N.A. Sala IX: 6.9.4. Compañía de Jesús.
} 
de referências que concediam a um tempo histórico anterior aos ataques bandeirantes da quarta década do século XVII. E como prova do que afirmavam, utilizavam-se de um título de D. Juan Blasques de Balverde, ao qual foi desconsiderado por não provar "legitimidade".

As afirmações do padre Anselmo de la Matta, outro juiz da decisão, indicam que faltaria ao povo de San Xavier garantir através do referido título (lê-se também merced) os términos e limites correspondentes. Ademais, ao seu crivo, uma estância apenas seria suficiente para concentrar os gados referentes ao povo. Para tanto, sabemos também, que tal contundência foi mantida porque os índios daquela redução alegavam que o território onde constavam os ervais, lhes pertenciam por "direito natural", muito por conta de um índio chamado D. ${ }^{\mathrm{n}}$ Fran. ${ }^{\mathrm{co}}$ Nongê. Situação que foi acintosamente negada pelo religioso em questão.

Noutra declaração, desta vez, de Pablo Restivo, chega-se ao conhecimento de que o caso já havia envolvido outra sentença de juízes e como tal deveria acompanhar a decisão de tempos anteriores. Para isso, teve de recorrer como suporte a um testemunho do padre Christobal Altamirano, que segundo consta, os conheceria desde a época de sua infidelide. Das suas afirmações e segundo consta, tendo a participação de alguns índios da época [sic], chegou-se à conclusão de que os ervais não necessitariam ser aproveitados, todavia, deveriam preocupar-se em resguardar a estância. Naquilo que poderíamos considerar ser uma opção ou escolha, não deixa de ser uma estratégia para apropriar-se de um território que já continha um objeto agregado à sua antiga estrutura: o gado. Para tanto, um questionamento por ora se faz ainda mais necessário: que garantia teríamos ao tentar destituir a hipótese de que o território que reservava o erval em disputa não seria o mesmo que estaria a amparar a estância mencionada?

Até o momento, as sugestações que apresento se valeram também de formulações mal compreendidas à época, dos próprios problemas. Ilustrações como a que envolveu a crônica do padre Calvo indicam que o povo de San Xavier teria se apropriado de uma declaração do padre Crhistobal de Altamirano, na qual reafirmaria uma consulta aos "primeiros padres", entretanto, não faz menção alguma ao nome deles. O pouco que suspeitamos é que o religioso acabou consultando os padres que estiveram ao momento das fundações. Além da consulta, o religioso fez uso da sua experiência individual em missões para reafirmar que não houvera tido dentre os primeiros moradores do pueblo de San Xavier algum cacique que fosse proprietário do território em lítigio. Ainda mais que ele próprio julgava que "jamás sus abuelos, se avían atrevido a tener chacaras".

As descrições de Domingos Calvo acompanhavam as observações feitas por outro religioso, o padre Paulo de Orduña. Ele teria afirmado que os ervais era uma prática a priori 
recente, diante do contexto em vigência. Segundo consta, Orduña teria confirmado que: "jamas pueblo alguno tubeo yerbal proprio asta de unos $\underline{20}$ anos a esta parte, que un Indio llamado Francisco Nongê se agrego al pueblo dela Concep. ${ }^{\mathrm{n}}$ delo qual se colige, q. ${ }^{\mathrm{e}}$ los primeros fundadores y pobladores de dho pueblo de S. Xavier, no fueron, ni pudieron ser dueños de yerval alguno".

Ao decorrer das observações, chega-se ao conhecimento de que o padre Christobal Altamirano, na condição de padre Superior teria concedido direito a San Xavier para formar uma "estanzuela", uma vez que, "los indios del dicho pueblo se allaban necesítados de tierras, por haver desamparado la chacarería, que tenían ala otra banda del Uruguay la qual chacarería la desampararon por míedo delos infieles Tapiiy”. Na opinião de Calvo, a doação feita por Altamirano não teria valor algum, haja vista que, "no pretendio por sua firma authoriçar, ni dar por verdaderas dhas raçones, porq. ${ }^{\mathrm{e}}$ no podia en conciencia, por saber, que son ciertam. ${ }^{\text {te }}$ falsas lo que afirma com juram. ${ }^{\text {to, }}$.

As críticas de Calvo, de modo a tornar o caso favorável à sua forma de interpretar, foram extendidas à doação feita por D. Juan Blazquez de Valverde. Conforme sua opinião "la dicha donación no es perfecta donacíon". Dentre outros argumentos o religioso fez questão de indicar que o direito de posse teria sido falso e fraudulento. Dentre as críticas realizadas, pois, é possível contextualizar uma das lógicas de colonização mantida dentre os religiosos.

Tornou-se recorrente transpassar a hipótese que muitos dos personagens envolvidos ao tempo inicial de conquista tiveram de adotar estratégias que atraíssem os índios aos tratos cristãos de modo a revelar um estilo de sociedade receptivo à prática da guerra e à conquista de territórios. E, ao que indica o caso de pleito que acabou envolvendo San Xavier e Concepción, demonstra que os índios xavieristas foram incentivados a conquistar novos territórios. E a isso não interessariam os meios. As práticas por outro lado, promoveram à comunidade um sentimento de pertença que parece ter sido questionada ao longo de quatro décadas de desgaste. Contudo, no que compete à defesa de San Xavier, o povoado teria se preocupado em indicar que:

El pueblo de S. Xavier hallo un yerbal quantioso 3, ô 4 legoas distante por línea recta del Pueblo. Siendo Sup. ${ }^{\text {or }}$ destas Doctrinas el P. ${ }^{\text {e }}$ Sebastían de Toledo. El pueblo dela Concep. ${ }^{\text {on }}$ pretendío ser suio dho yerbal por decír que dho yerbal allado era ñucura yerbal próprio del pueblo dela Concep. ${ }^{\text {on }} \mathrm{q}$ porque se incluía en un titulo de merced que el P. Sup. ${ }^{\text {or }}$ Sebastian de Toledo le hacía demas cíen léguas de tierras para cuia prueba exíbio un quasi titulo o quasi merced de dhas $\underline{100}$ leguas de tierra por ser solo convenío del pleito que el pueblo dela Concep. ${ }^{\text {on }}$ tenía com S. Luís (Grifo autor) ${ }^{11}$.

\footnotetext{
${ }^{11}$ Mantemos as abreviaturas conforme se atesta na documentação de época. A.G.N.A. Sala IX: 6.9.4. Compañía de Jesús.
} 
Chegamos aqui a uma constatação especialmente incomum. O que de fato garantia um quasi titulo ou uma quasi merced? De igual modo, como mensurar os aproveitamentos quando deslocados a experiências de longa duração?

Caso recorramos ao documento que traz por chamada as Respuestas del P. Raphael $\hat{a}$ las perguntas del P. Procurador de Misiones, Roque Ballester; as questões acima direcionarão a uma preparação racional para situações insuficientes e insustentadas ao curso das manifestações que compunham aquelas experiências. É preciso, pois, sublinhar que o ato de provar a veracidade das informações admitidas aos casos de lítigios, bem como a legitimidade de posse, exigiu por parte daqueles povoados documentos que comprovassem situações relacionadas a dois tempos históricos prioritariamente distintos: o tempo vigente das suas atividades e o processo de fundação que deixava de ser parte de um passado.

Num dos momentos mais decisivos do conflito, Roque Ballester passa a investir na retórica de testar a memória efetiva daquelas comunidades, até não mais poderem apresentar laços parentais. Sem maiores avanços e talvez com poucos recursos de barganha para solucionar o impasse, eis que Ballester recorre a uma prática especialmente inusitada: exigir que as manifestações de ancestralidade fossem comprovadas por meio de algum documento que demonstrassem a procedência, a origem e a posse daqueles. Posto isto, a preocupação alcançou um nível de seriedade que foram necessárias outras novas explicações ou revisões a antigos títulos de propriedade, como deixa a demonstrar a sequência que segue:

La primera fue. Si tal merced de tierras era tan legitima que por virtud della pudíera justamente el Pueblo dela Concep. ${ }^{\text {on }}$ tener el domínio delas $\underline{100}$ legoas de teierra que pretende por virtud de tal titulo. $\mathrm{O}$ si dha merced era ínoficiosa y del todo íncapaz de darle dho el Dominio. La segunda sí caso que dha merced de tíerras fuesse del todo legítima la sentencia que díeron los Juezes que dho yerbal hallado sobre que se el lítigio, era deLa Concep. ${ }^{\text {on }}$ fue del todo legitima atento al Juízio natual solo q no el estrepito judicial de tal manera, que no sea digno de revocación, ní em intíende, ô si se deve corregir em mendar, ô revocar. La tercera, sí caso que dha merced y sentencía se decia Corregír em mendar y revocar podia V. R. corregírla en mendar la, ò revocarla sin contravenir à el orden de Roma de que un Prov. ${ }^{1}$ no de saga lo que otro hizo; por aver confirmado dha merced y sentencia el P. ${ }^{\mathrm{e}}$ Prov. Símon de Leon Antecessor de V.R. corregir en mendar,ò revocar dha merced y sentencia no obstante dha confirmación sín contravenir al dho orden de Roma; Lo cerca de siere valida cínoficios dha quase merced que era el primer parte se puse V.R. das cosas de hecho. Dos de derecho, sivil y natural. Y una se echo y de derecho sivil y religioso ${ }^{12}$.

Analisados atentamente os julgamentos, fica nítido que a transformação de uma sociedade não se dá apenas ao impulso de dominar territórios e produtos alheios. Todavia, há

${ }^{12}$ A.G.N.A. Sala IX: 6.9.4. Compañía de Jesús. 
boas razões para supor, também, que em alguns momentos foi necessário investir em argumentos que pudessam confundir um traçado original de organização ao invés de conciliar esforços e concensos de envolvimento.

Por essa definição sustentamos a tese de que a distribuição de uma graça, em verdade, servia como um dispositivo arbitrário que acabava levando a um esquecimento sistemático, daqueles povoados para com a sua própria originalidade. De qualquer forma, pelo que podemos constatar o território foi ocupando uma importância em decorrência de um canavial, madeira, mel e cera. Essa, no entanto, é precisamente a questão. E não por acaso, acabou por reverter ao padre Superior alguns adjetivos que acabaram por descrevê-lo como "una persona no legítima para pribar alos Indios del derecho de naturaleza y ser las tierras con naturalización". A contrariedade para com o personagem ficou ainda mais saliente por meio da seguinte manifestação:

Principalm. ${ }^{\text {te }}$ no siendo el P. ${ }^{\text {e }}$ Sup. ${ }^{\text {or }}$ persona legitima para probar alos indios del derecho sivil y maior queles dio un oydor visitado Governador en nombre del Rey y en que an tenido possesíon actual por quarenta y dos años. Que sean daño de tercero y de otro que mejor derecho tenga segun el derecho Religioso se infiere. Porque como consta delos autos el pueblo de $\mathrm{S}$. Xavier a tenido domínio possesion enla forma u manera quelos Provinciales pueden enlas tierras dela otra banda de frente y de un lado y de otro por titulos del P. ${ }^{\mathrm{e}}$ Prov. ${ }^{1}$ Thomas Donvidas siendo V.R. su secretario pues el año $\underline{89}$ las confirmo y dio de nuevo sin necessario fuesse todas las tierras que el pueblo de S. Xavier posseia dela otra banda en virtud delos titulos del oydor Blasquez de Valverde. Y en virtud de dhos titulos confirmativos del P. ${ }^{\mathrm{e}}$ Thomas Donvidas Prov. a posseído el pueblos de S. Xavier la otra banda por frente y la dos teniendo estancia chacaras sacando miel y sera como lo pruebna onze firmas de onze $\mathrm{P}^{\text {es }}$ todo lo qual prueba el domínio y possesíon segun el derecho Religioso Superio y Legitimo que el Pueblo de S. Xavier atenido enlos montes y tierras del litigio y por tanto se infiere se dha quasi merced en daño de tercero y contra quíen mejor derecho tíene segun el derecho religioso y maior porque segun consta delos autos y dela dha quasí merced todo quanto seda y y confirma por dhos títulos del P. ${ }^{\mathrm{e}}$ Prov. ${ }^{1}$ al pueblo de S. Xavíer selo quíta el P. Sup. ${ }^{\text {or }}$ no es persona legítima para revocar y anullar lo echo del Padre Prov. ' que le aprobo y confírmo síendo sín daño de tercero, y de otro que mejor derecho tenga, y no de otra manera, porque como consta delos autos, dandole afirmar el P. ${ }^{\mathrm{e}}$ Petragrassa un título en donde se contíenen los termínos del Convenio de donde se origino dha quasí merced todos escrítos de Letra dela parte temiendo el que enla verdad era, añadio el P. ${ }^{\mathrm{e}}$ Prov. ${ }^{1}$ de su Letra ${ }^{13}$.

Sem dúvida, a determinação por parte de Roque Ballester foi dada com vistas a constituir um interesse próprio para com propósitos que ele próprio acreditou serem viáveis e, sobretudo realizáveis do ponto de vista histórico. Ao seu ver, os impasses só seriam

\footnotetext{
${ }^{13}$ A.G.N.A. Sala IX: 6.9.4. Compañía de Jesús.
} 
resolvidos quando confrontadas as argumentações que cada comunidade defendia. A incapacidade por formulações mais precisas acabou por revelar a gravidade do caso.

Voltados a imputar alguma responsabilidade à redução de Concepción, eis que San Xavier acabou por rememorar as ameaças de morte que haviam sofrido por parte dos seus oponentes. A princípio, o motivo que levou ao acirramento dos ânimos deu-se em decorrência do padre superior Angelo Petragrassa ter aconselhado aos índios de San Xavier a açoitar e envergonhar os índios de Concepcíon que se atrevessem a infringir novamente na propriedade que lhes cabia preservar.

Por esta demonstração é possível salientar que a celeuma deixou profundas marcas e consideravelmente favoreceu para que aqueles pueblos mantivessem entre si um recíproco desgaste. Ou tal qual indicam as palavras de Rafael, retornariam ao "estado el dolor y la causa en píe síempre ade aver disensíones entre los dos pueblos que cessaron con revocar dha quasí merced" $"$. Com efeito, a indefinição acabou por estimular os índios mais antigos dos povos a legitimarem memórias e atuações que fizessem valer a ocupação que mantinham até então.

Neste meandro, até foi tentada a criação uma equipe de reconhecimento para melhor definir o episódio. A mesma chegou a ser composta pelos padres Domingo Calvo, Juan Antonio Palacios e Francisco de Medina. Todavia, a inspeção nunca aconteceu, pois ao que consta, a comitiva foi impedida de chegar no território em disputa, porque foram surpreendidos pela cheia de um arroio [sic] que dava acesso àquele. Por último, mas não menos importante, decidiram pela anulação da sentença e, sem maiores esclarecimentos, voltaram a confirmar o direito de posse e de exploração para o povo de Concepción.

Paradoxalmente, uma vez conhecida essa manobra, fica patente que os jesuítas condicionavam seus comportamentos de modo proteiforme. Por outro lado, dificilmente os povos indígenas perdiam a oportunidade de reinvindicar antigos territórios, pois ao fazer isso não só confundiam o registro oficial das decisões, como também, ratificavam, forjavam e recriavam espaços que lhes permitiam reposicionar o seu "modo antigo de viver" (MONTEIRO, 1992, p. 476).

Em face da consagração possível: últimas constatações acerca dos pleitos pueblerinos e a transformação de uma região histórica

${ }^{14}$ A.G.N.A. Sala IX: 6.9.4. Compañía de Jesús. 
As tentativas cada vez mais ousadas, sobretudo das últimas décadas, têm demonstrado que os argumentos em referência ao contexto reducional se ajustam ao contraditório ${ }^{15}$. E este ensaio não foge à regra. Sinteticamente, porque é praticamente impossível de ser negado que o trato reducional compôs uma sucessão de eventos que acabaram por arrimar aquelas comunidades originárias numa condição existencial e direta, para com uma práxis de envolvimento anteriormente impraticável. Em larga medida, essa concepção teve de ser ancorada através de escolhas e determinações que a própria sociedade "envolvente" foi provocando ao decorrer dos anos. Nathan Wachtel chegou a indicar uma orientação nesse sentido, quando afirmou que:

Certas estruturas conseguiram sobreviver, mas fragmentadas e separadas de seu contexto original e transpostas para o mundo colonial. Não obstante, essas continuidades parciais garantiram que tradições nativas - um tanto modificadas - fossem passadas adiante, enquanto ao mesmo tempo sustentavam a hegemonia espanhola (WACHTEL, 2004, p. 220).

É uma situação inteligível e natural quando considerada a mudança decorrente e todos os feitos que tiveram de ser ajustados, proporcionalmente às aspirações de conquista ou que incentivaram na descaracterização, mesmo que "temporariamente", das referências que transmitiam alguma importância para os indígenas ${ }^{16}$. Vale dizer, que por meio desta alternativa foi possível condicionar uma motivação excessiva de época: conquistar grupos para assim confirmar "territórios de memória". Mas a noção, no que pese seu aproveitamento histórico, revela que a desestruturação do meio nativo só foi possível porque paralelamente a isso, houve necessidade de investir numa "linguagem de convívio" que parece ter sido encantadora ao revés do inopinado. O que prova que o projeto jesuítico, antes de qualquer trajetória insuperável, previu cumprir um envolvimento permanente por parte daqueles que se colocaram à caminho do mesmo.

Disso se segue que, para a preservação desse objetivo supremo não foi necessário apenas fragmentar o predomínio de outrora, senão renunciá-lo a uma razão que os fizesse distinguir a "ordem das coisas" para a "ordem dos religiosos". Estas observações gerais, ao que consta, mostraram-se necessárias para repor em seu contexto real o reflexo e por conseguinte o prolongamento colonial junto daquelas comunidades.

\footnotetext{
${ }^{15}$ Alinham-se nesse contexto a relação que segue: MALDI, 1997; DOS SANTOS, Maria C.; BAPTISTA, Jean, 2007, p. 242-251; GIUDICELLI, 2011.

${ }^{16} \mathrm{~A}$ interpretação do território tal como concebemos procura se integrar à linha sugerida pela etnografa Branislava Susnik. Em especial o que ela atestou como os të̈ys, isto é, o agrupamento das parcelas indígenas por meio dos cacicados e que ao final garantiu a formação dos povoados. Nesse caso, conferir: SUSNIK, 1965; SUSNIK, 1975.
} 
Bem ponderados os sentidos, abre-se um problema completamente novo sobre o qual vale a pena fazer um questionamento de momento: Como tratar as políticas de privilégios como as quasi merced num contexto amplamente diverso e indicifrável, se comparado com os ritos de uma sociedade de antigo regime ${ }^{17}$ ?

Em suma, as graças atendiam a uma condição de momento, sem a necessidade de extender definitivamente uma relação de vassalagem direta daquelas comunidades para com o reino distante da Espanha. No fundo, o que se acha explícita ou implicitamente na ação de legitimidade é uma pormenorizada pista que se ajusta recorrentemente no discurso dos padres por meio da frase "eherencia legitima".

Sem desconsiderar esse fato, e os diversos outros sentidos em que poderíamos ainda insistir, não chega a admirar que algumas situações de pleitos não retratam às claras quão intencional tivera sido os esforços dos religiosos, para enfraquecer a memória indígena e assim condicionar o seu próprio aspecto terrificante ao cenário. Ocorre, que anterior à conquista colonial, muitos indígenas, quiçá a grande maioria, mostravam-se desconhecedores da noção de propriedade.

Acerca disso, podemos dizer que por meio de uma combinação delicada de observações sutis, quaisquer que fossem as intenções expressas, um fato é inegável: Com o passar dos anos, cada redução acabou por adotar seu regramento particular de modo satisfazer o referido propósito. Naturalmente que há nisto implicações. E, não por menos, é preciso avançar na direção de superar essas limitações.

Por fim e sem maiores correções, uma coisa é certa: os pleitos pueblerinos não só justificam a consagração de interesse (s) em detrimento de outro (s), como também, corroboram voluntariamente ou involuntariamente com um léxico interpretativo que não descansa em salientar que "por parte de un pueblo de una tierra o un derecho común por costumbre desde tempo inmeroriables a menudo no expresa un hecho histórico, sino el equilibrio de fuerzas (HOBSBAWN; RANGER, 2002, p. 8).

\footnotetext{
${ }^{17}$ Para compreender o contexto ao qual nos dirigirmos, ver: LAMPÉRIÈRE, , 2000; HESPANHA, 2006;
} HESPANHA, 2010. 


\section{Acervo de consulta}

A.G.N.A. Archivo General de la Nación Argentina. Buenos Aires.

\section{Referências bibliográficas}

ARMANI, Alberto. Ciudad de Dios y ciudad del Sol. El "Estado" jesuita de los guaraníes (1609-1768). México: Fondo de Cultura Económica, 1996.

BARCELOS, Arthur. O mergulho no seculum: exploração, conquista e organização espacial jesuítica na América espanhola colonial. Tese de Doutoramento em História. Porto Alegre. PUCRS, 2006.

CARDIEL, Joseph. Las misiones jesuiticas. Edição, introdução e notas de Héctor S. Ollero. Madrid: Historia 16, 1988.

DOS SANTOS, Maria.C.; BAPTISTA, Jean. Reduções jesuíticas e povoados de índios: controvérsias sobre a população indígena (séc. XVII-XVIII). In: Revista de História da Unisinos, Maio/Agosto, p. 242-251, 2007.

GIUDICELLI, Cristopher. Las tijeras de San Ignacio. Misión y clasificación en los confines coloniales. In: Saberes de la convesión: jesuítas, indígenas y imperios coloniales en las fronteras de la cristandad. Editado por WILDE, Guillermo. Buenos Aires: Editorial SB, 2011. GRUZINSKI, Serge. El pensamiento mestizo. Cultura ameríndia y civilización del Renacimiento. Barcelona. Ed. Paidós, 2007.

HESPANHA, Antonio M. A mobilidade social de antigo regime. In: Tempo, vol. 11, $\mathrm{n}^{\mathrm{o}} 21$, 2006.

Imbecillitas. As bem aventuranças da inferioridade nas sociedades de Antigo regime. São Paulo: Annablume, 2010.

HOBSBAWN, Eric; RANGER, Terence. La invención de la tradición. Barcelona, Editorial Crítica, 2002.

JARQUE, Francisco. Las misiones jesuíticas en 1687. El estado que al presente gozan las misiones de la compañía de Jesús en la provincia del Paraguay, Tucumán y Rio de la Plata. $1^{\mathrm{a}}$ ed. Buenos Aires: Academia Nacional de la Historia. Estudio preliminar de Ernesto J. A. Maeder, 2008 [1687].

KERN, Arno. O processo platino no século XVII: da aldeia Guarani ao povoado missioneiro. In: Folia Historica del Nordeste. Argentina: Universidad Nacional del Nordeste, 1984.

LAMPÉRIÈRE, Annick. La representación politica en el império español a finales del antiguo régimen. In: Dinámicas de Antiguo Régimen y orden constitucional: representación, justicia y administración en Iberoamérica siglos XVIII-XIX. Editado por Marco Bellingeri. Torino: Otto Editore, 2000.

MALDI, Denise. De confederados a bárbaros: a representação da territorialidade e da fronteira indígena nos séculos XVIII e XIX. In: Revista de Antropologia. Vol. 40, nº 2, USP, São Paulo, 1997.

MONTEIRO, John. Os guaranis e a história do Brasil meridional. In: História dos índios no Brasil. CARNEIRO DA CUNHA, Manuela (org.). São Paulo: Companhia das Letras: Secretaria Municipal de Cultura: FAPESP, 1992.

PACHECO DE OLIVEIRA, João. Ensaios de antropologia histórica. Rio de Janeiro: Ed. UFRJ, 1997.

PINTO; Muriel; MAURER, Rodrigo. Quando a geo-história avança sobre os significados de um espaço urbano: as paisagens culturais e as transformações identitárias da fronteira Brasil Argentina. In: Eure, vol. 40, nº 120, Mayo 2014: 135-158. 
SUSNIK, Branislava. El indio colonial del Paraguay I: El Guarani colonial. Asunción: MEAB, 1965.

Aproximación a la realidad vivencial y al ethos existencia en el Paraguay colonial. Ambiente rural. In: Estudios Paraguayos, vol. III, nº 2, Asuncion, 1975.

WACHTEL, Nathan. Os índios e a conquista espanhola. In: História da América Latina: América Latina colonial. Vol. 1. Editado por Leslie Bethell, $2^{a}$ ed. São Paulo: Editora da USP, Brasília, DF: FundaçãoAlexandrede Gusmão. 2002.

WILDE, Guillermo [et.al]. Saberes de la conversión: jesuitas, indígenas e imperios coloniales en las fronteras de la cristandad. $1^{\text {a }}$ ed. Buenos Aires: SB, 2011. 